\title{
Isolation of detergent resistant microdomains from cultured neurons: detergent dependent alterations in protein composition
}

\author{
Ritchie Williamson ${ }^{1,2^{*}+}$, Andrew J Thompson ${ }^{1 \dagger}$, Mika Abu $^{1}$, Abdul Hye ${ }^{1}$, Alessia Usardi ${ }^{1}$, Steven Lynham',
} Brian H Anderton ${ }^{1}$, Diane P Hanger ${ }^{1}$

\begin{abstract}
Background: Membrane rafts are small highly dynamic sterol- and sphingolipid-enriched membrane domains that have received considerable attention due to their role in diverse cellular functions. More recently the involvement of membrane rafts in neuronal processes has been highlighted since these specialized membrane domains have been shown to be involved in synapse formation, neuronal polarity and neurodegeneration. Detergent resistance followed by gradient centrifugation is often used as first step in screening putative membrane raft components. Traditional methods of raft isolation employed the nonionic detergent Triton X100. However successful separation of raft from non-raft domains in cells is dependent on matching the detergent used for raft isolation to the specific tissue under investigation.
\end{abstract}

Results: We report here the isolation of membrane rafts from primary neuronal culture using a panel of different detergents that gave rise to membrane fractions that differed in respect to cholesterol and protein content. In addition, proteomic profiling of neuronal membrane rafts isolated with different detergents, Triton X100 and CHAPSO, revealed heterogeneity in their protein content.

Conclusions: These data demonstrate that appropriate selection of detergent for raft isolation is an important consideration for investigating raft protein composition of cultured neurons.

\section{Background}

It is now accepted that lateral organisation occurs in membranes giving rise to distinct membrane domains characterised by differing lipid and protein composition. Membrane rafts are one such specialised membrane domain that has received considerable attention. Defined as small heterogeneous highly dynamic sterol- and sphingolipid-rich microdomains that can compartmentalise cellular processes [1], they have been reported to be integral to a wide range of cellular processes including cell signalling, endocytosis, and membrane trafficking [2]. Central to the study of membrane rafts is their detergent insolubility. Membrane rafts are enriched in cholesterol, sphingolipids and lipid modified proteins

\footnotetext{
* Correspondence: R.Williamson@dundee.ac.uk

† Contributed equally

'MRC Centre for Neurodegeneration Research, Institute of Psychiatry, King's College London, London, UK

Full list of author information is available at the end of the article
}

such as glycosylphosphatidyl (GPI)-anchored proteins. It is thought that the tight packing of sphingolipids long saturated acyl chains and intercalation of cholesterol allows for a more structured and rigid membrane organisation similar to the liquid ordered (Lo) phase of model membranes. This tight lipid packing separates them from the surrounding unsaturated gylcerolipid environment and also imparts resistance to detergent extraction [3].

Since the demonstration that GPI-anchored proteins were insoluble in non-ionic detergents including Triton $\mathrm{X} 100$ (Triton) at $4^{\circ} \mathrm{C}[4,5]$ and that this insolubility was cholesterol dependent [6], detergent resistant membrane (DRM) has subsequently become the operational definition for these isolated membrane domains. While detergent insolubility in itself is artifactual and does not accurately reflect pre-existing raft formation in cell membranes, detergent insolubility remains a powerful 
first step method for assigning potential membrane raft association.

Much of our current understanding of membrane raft biology has come from studies utilising the biochemical isolation of membrane rafts from epithelial and immune cells. More recently, the role of membrane rafts in central nervous system (CNS) function has been investigated and DRMs have been isolated from a variety of CNS tissue including both neuronal and glial cells as well as whole brain and synaptosomes [7-9]. Various functions have been attributed to these specialised membrane domains in neurons. Membrane rafts have been reported to be central to axonal growth cone guidance $[10,11]$ as well as synapse formation and maintenance [12]. Receptor clustering has also been attributed to membrane rafts $[13,14]$ including the recruitment of both excitatory AMPA and inhibitory GABA receptors to neuronal membrane raft domains $[12,15]$. Furthermore, accumulating evidence suggests a critical role for membrane rafts in neuronal signalling including endocytosis, trafficking, and neurotransmitter release (recently reviewed by Allen et al [16]). The role of membrane rafts in CNS function also extends to the pathogenesis of neurodegenerative disease including Alzheimer's disease (AD), prion disease and Parkinson's disease [16,17].

Since the postulation of the 'raft hypothesis' [18] and the isolation of membrane rafts as DRMs, a number of different detergents have been employed in the technical preparation of DRMs. The non-ionic detergent Triton is generally regarded as the gold-standard detergent for DRM preparation and has been used in initial studies characterising neuronal culture DRM composition $[19,20]$. Comparison of DRMs isolated with different detergents revealed altered protein and lipid composition [21-23] giving support to the concept of compositional heterogeneity underlying the functional heterogeneity of membrane rafts [24]. In addition, celldependent variation of DRM composition has also been reported [25] highlighting the importance of matching an appropriate detergent to specific tissue under investigation.

A growing body of literature supports an important role for membrane rafts in neuronal functioning. Given the observation that DRM compositional differences are cell type dependent we characterised DRMs isolated from primary neuronal cell culture using a panel of different detergents. The efficiency of DRM isolation was assessed by comparing the efficiency of recovery of cholesterol, total protein, and raft marker proteins in the isolated DRMs with total lysate. We further specifically characterised the proteomic composition of neuronal DRMs isolated with Triton, the gold-standard detergent for membrane raft isolation, and 3-(3-cholamindopropyl)-dimethylammonio-2-hydroxy-1-propanesulfonate
(CHAPSO), the detergent that showed the best separation of DRMs from bulk lysate as determined by cholesterol and flotillin-1 content, by proteomic profiling using 1 D SDS-PAGE separation followed by LC-MS/ MS (GeLC-MS/MS). We report here that DRMs can be isolated from primary neuronal cultures with a number of different detergents and that the composition of DRMs with respect to cholesterol and protein content is dependent on the specific detergent used. Furthermore, protein profiling using mass spectrometry and biochemical characterisation of neuronal DRMs isolated using different detergents lends support to the concept of raft heterogeneity.

\section{Results}

Isolation of neuronal DRMs using Triton

Detergent resistant membrane rafts were isolated from primary cortical cells using extraction with the nonionic detergent, Triton, followed by sucrose density centrifugation. Raft localisation was detected by SDS-PAGE of sucrose gradient fractions followed by Western blotting for the established raft protein flotillin-1. Figure 1 shows a typical distribution of flotillin-1 in fractions from the sucrose gradient. As expected, DRMs were found in the low-density fractions (fractions 4 and 5) corresponding to the $5 \%$ and $35 \%$ sucrose interface. A large proportion of flotillin was also detected in the high-density fractions (fractions 10-12). To examine the specificity of the DRM containing fractions and to ensure that traditional non-raft domains were fully solublised by Triton, Western blots of sucrose gradient fractions were analysed for the presence of the non-raft proteins calnexin and the transferrin receptor. Figure 1 illustrates a typical profile of calnexin and transferrin receptor immunolabelling of sucrose gradient fractions. Both calnexin and transferrin receptor were absent from the low-density DRM fractions 4 and 5 and concentrated in the high-density non-DRM fractions 10-12 demonstrating a clear separation between raft and nonraft proteins.

\section{Detergent specific distribution of flotillin-1 in sucrose gradients}

It has been reported that isolation of DRMs with different detergents in differing cell populations gives rise to altered protein composition supportive of the idea of raft heterogeneity. To examine the effect of different detergents on identically cultured neuronal cells, we isolated DRMs with a panel of different detergents. Nonionic Brij detergents have previously been employed to isolate lipid rafts from a variety of cells and tissue. In addition both the zwitterionic detergents CHAPS and CHAPSO have been used to isolate lipid rafts all of which have been reported to give rise to different 


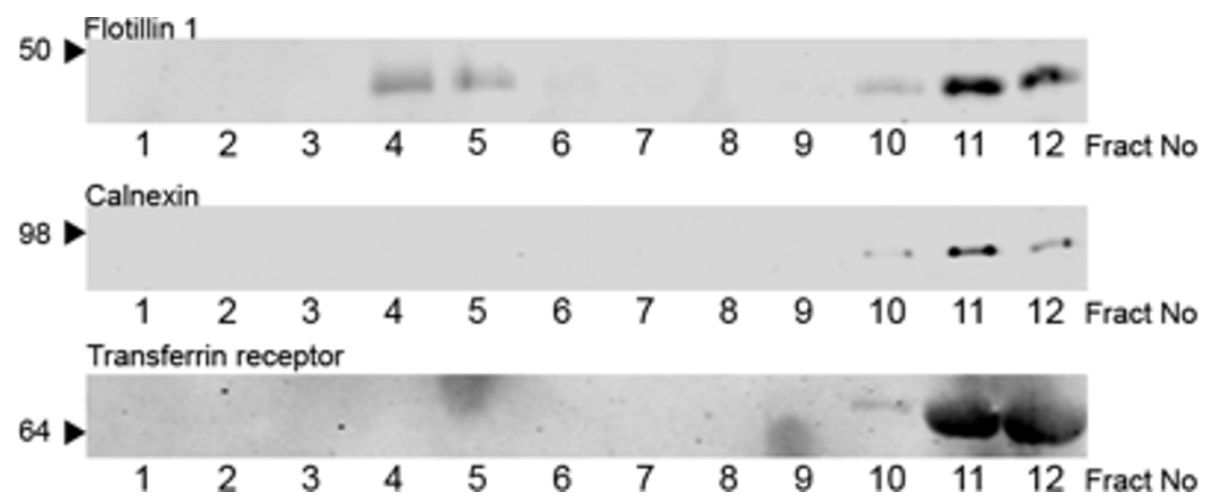

Figure 1 Distribution of raft and non-raft components in Triton isolated neuronal DRMs. Triton lysates of primary cortical cultures were fractionated by sucrose gradient ultracentrifugation. Equal volumes of each fraction was analysed by Western blotting with antibodies to the indicted proteins. Apparent molecular mass is indicated to the left.

compositions of raft-associated proteins in relation to Triton. We therefore examined the effect of the detergents, Triton, Brij 58, Brij 98, and CHAPSO, on the distribution of the lipid raft marker flotillin 1 . We included Brij 98 in our study as this detergent has previously been employed to isolate DRMs at $37^{\circ} \mathrm{C}[25,26]$. After sucrose gradient centrifugation a light scattering band was detected at the 5-35\% sucrose interface for Triton, CHAPSO, Brij 58, and Brij 98. Figure 2 shows the distribution across the sucrose gradient fractions of the raft marker flotillin-1 for all detergents. For all detergents, flotillin-1 appeared to partition into two distinct sets of fractions, the low-density fractions (fractions 4 and 5) and the high-density fractions (fractions 10-12). However, there was a clear difference in the selectivity of detergents to enrich flotillin-1 in the low-density fractions. As noted previously, the most striking difference was observed in the distribution of flotillin-1 in the
Triton extract. Here, the majority of flotillin-1 was found in the high-density soluble fractions and that only a minor fraction of total flotillin-1 partitioned into the low-density DRM fractions. Quantitation of Western blots revealed that DRM isolation by Triton extraction resulted in the lowest enrichment of flotillin-1, a mean \pm SE of $7.5 \pm 2.4 \%$ total flotillin-1 (Figure 2B) when compared to other detergents. In contrast, isolation of DRMs with the other detergents resulted in a greater enrichment of flotillin-1, CHAPSO (47.3 \pm 8.6 ), Brij 58 $(33.4 \pm 8.8)$, and Brij 98 (25.3 \pm 5.3$)$. High intensity scanning of all the membranes revealed a clear separation of flotillin-1 positive bands between the highdensity and low-density fractions and no presence of flotillin-1 was found in fractions 7-9. DRMs isolated with the different detergents were further examined for the presence of non-raft proteins. The transferrin receptor or calnexin could not be detected in the low-density
A
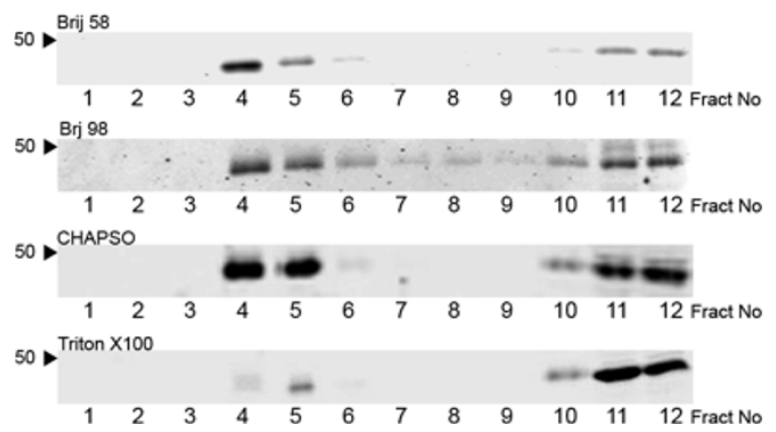

B

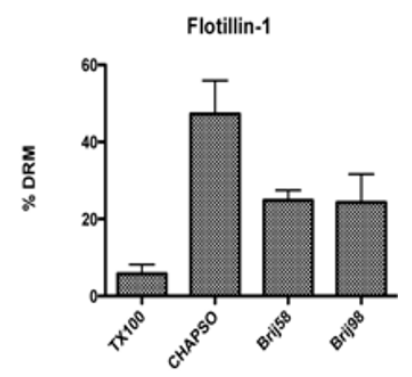

Figure 2 Altered distribution of flotillin-1 in neuronal DRMs isolated with different detergents. A. Equal volumes of primary cortical lysates were incubated with the indicated detergents at a final concentration of $1 \%(\mathrm{w} / \mathrm{v})$ prior to fractionation by sucrose gradient centrifugation. Equal volumes of each fraction was analysed by Western blotting with an antibody to flotillin-1. Apparent molecular mass is indicated to the left. All blots are representative of at least three independent experiments. B. Quantification of flotillin-1 in neuronal DRM fractions isolated with indicated detergents expressed as \% DRM enrichment of total gradient flotillin-1; $n=3$. 
fractions of any of the sucrose gradients isolated with any of the detergents and were detected solely in the high-density fractions (data not shown).

\section{Distribution of protein and cholesterol in sucrose gradient fractions from different detergents}

Next we analysed the distribution of cholesterol and protein in the sucrose gradient fractions isolated with our panel of different detergents (Figure 3). The general pattern of protein distribution in the gradient fractions was similar for all the detergents tested with the largest amount of protein detected in the high-density fractions (fractions 10-12) and a smaller amount of protein spread out over the lower-density fractions (fractions 3-5). There was a striking difference in the distribution of cholesterol in the gradient fractions between the different detergents. For Triton gradients, the distribution of cholesterol mirrored the distribution of protein with the majority of cholesterol being detected in the highdensity fractions and only a small proportion of cholesterol being isolated in the low-density fractions. The cholesterol distribution in the CHAPSO and Brij 58 gradients showed that the bulk cholesterol was found predominantly in the low-density fractions with only a trace being detected in the high-density fractions. For the Brij 98 gradients there was a clear bimodal distribution of cholesterol into both the low-density fractions and the high-density fractions although the peak for cholesterol content was higher in the low-density fractions than for the high-density fractions, similar to the cholesterol distribution reported in other neuronal studies [27].

The total protein and total cholesterol content as well as \% DRM enrichment from sucrose gradients fractions are summarised in Table 1. Triton gradients had the lowest \% DRM cholesterol enrichment with a mean \pm SE of $4.2 \pm 1.7 \%$ while CHAPSO gradients had the highest \% DRM enrichment of cholesterol, $84.0 \pm 6.9 \%$.

As CHAPSO gradients yielded the highest distribution of the raft marker flotillin-1 and cholesterol in the low density fractions and Triton yielded the lowest distribution of flotillin-1 and cholesterol in the low-density fractions we next investigated the distribution of this marker in other primary hippocampal cultures and the neuroblastoma cell line SHSY5Y (Figure 4). Similar to primary cortical cultures, DRMs isolated with CHAPSO displayed an enrichment of flotillin-1 in the low-density

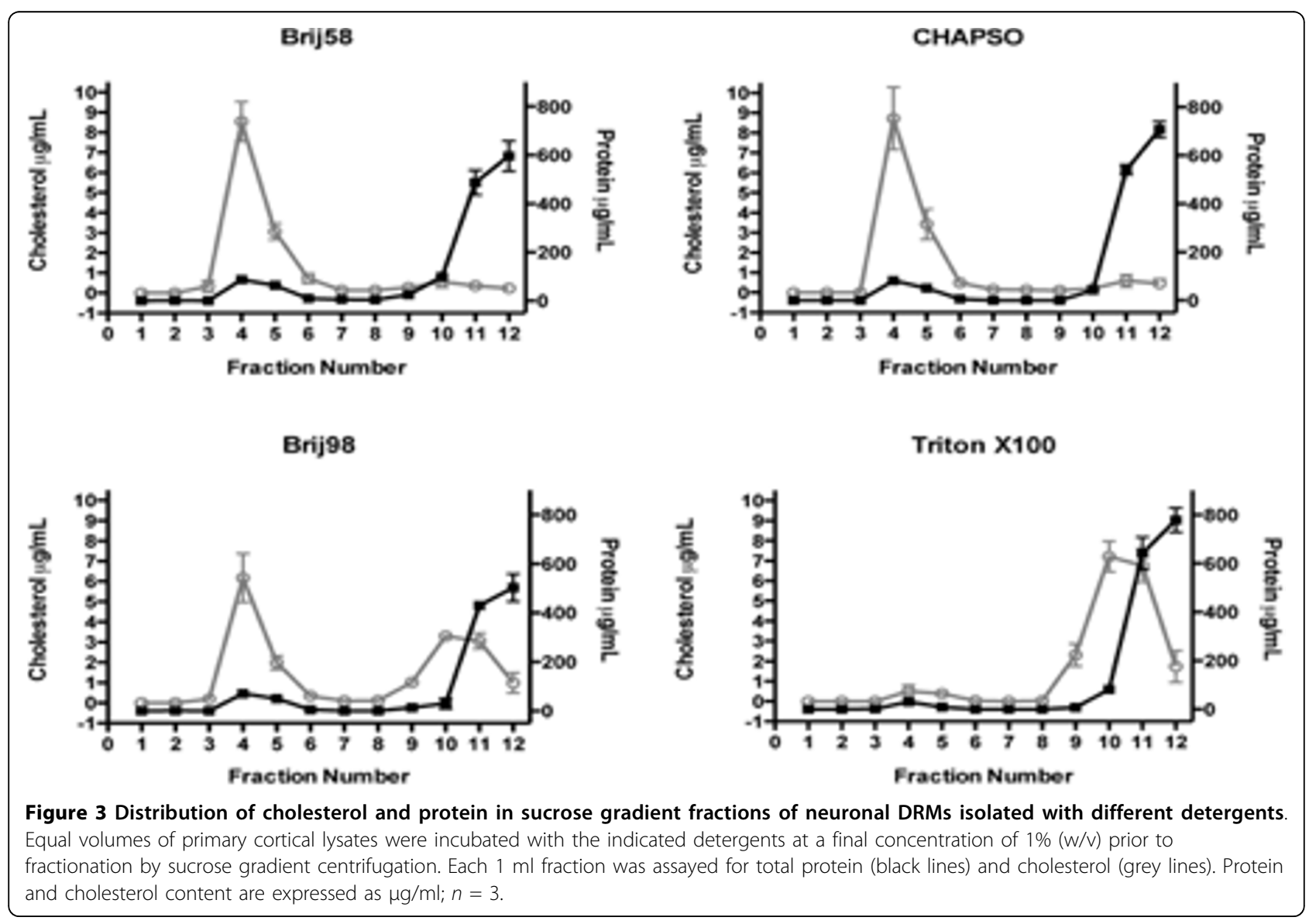


Table 1 DRM enrichment of protein and cholesterol

\begin{tabular}{lllll}
\hline Detergent & $\begin{array}{l}\text { Total gradient } \\
\text { cholesterol }(\boldsymbol{\mu g})\end{array}$ & $\begin{array}{l}\text { \% DRM cholesterol } \\
\text { enrichment }\end{array}$ & $\begin{array}{l}\text { Total gradient } \\
\text { protein }(\mathbf{m g})\end{array}$ & $\begin{array}{l}\text { \% DRM protein } \\
\text { enrichment }\end{array}$ \\
\hline Triton X100 & $19.0 \pm 2.9$ & $4.2 \pm 1.7$ & $1.55 \pm 0.109$ & $2.8 \pm 0.68$ \\
CHAPSO & $14.3 \pm 2.2$ & $84.0 \pm 6.9$ & $1.43 \pm 0.058$ & $9.3 \pm 0.49$ \\
Brij58 & $14.3 \pm 1.7$ & $81.2 \pm 5.6$ & $1.38 \pm 0.130$ & $10.9 \pm 0.33$ \\
Brij98 & $17.3 \pm 2.2$ & $46.9 \pm 5.7$ & $1.10 \pm 0.048$ & $10.9 \pm 0.32$ \\
\hline
\end{tabular}

fractions from both hippocampal and SHSY5Y cells when compared to DRMs isolated with Triton.

\section{Proteomic profile of neuronal DRMs}

The protein composition of DRMs isolated with the two detergents Triton and CHAPSO were comprehensively characterised by proteomic profiling. Isolated hippocampal DRM fractions were collected and concentrated by ultra-centrifugation. Whole DRM preparations were resolved by SDS-PAGE, visualised by staining with colloidal Coomassie blue, and the entire gel lane excised for in-gel digestion and LC-MS/MS analysis (Figure 5). In total, 2583 and 1876 unique peptide sequences were confidently assigned in the CHAPSO and Triton raft preparations, respectively. This corresponded to the identification of 437 and 288 proteins in the two preparations, consistent with the higher protein yield observed for CHAPSO DRM isolation. Additional file 1, Table S1 gives the complete list of proteins identified in each preparation along with Swissprot Entry numbers and proteomic characterisation. Many proteins commonly isolated in DRM preparations were identified in both profiles, 234 proteins where common to both DRMs while CHAPSO raft preparations had 203 unique proteins and Triton raft preparations had 54 unique proteins. Table 2 gives a summary of proteins identified in both the CHAPSO and Triton raft preparations. Proteins common to both preparations included tubulin, actin, and associated structural proteins; anion-selective and calcium channel/transporter proteins; GTP-binding proteins, ras-family members and other cell signalling proteins; and the raft marker proteins flotillin-1, flotillin-2 and Thy-1. Similarly to other neuronal DRM preparations, numerous proteins were identified that are not normally found in non-neuronal DRMs. These included the neuronal structural proteins brain acid soluble protein, neuronal growth regulator 1 and several contactins; and various synaptic proteins including syntaxins, neuroligins and neuromodulin.

Annotation of the protein profiles revealed proteomic differences between the two DRM preparations. In the CHAPSO preparation, 349 of 437 (80\%) of the proteins identified were classified as membrane proteins, compared to 185 of 288 (64\%) for Triton (Figure 6). Of these, 65 of the membrane proteins from the CHAPSO preparation were known to incorporate lipid modifications, compared to 53 in the Triton preparation. Of interest, slightly more non-membrane proteins were identified in the Triton preparation compared to the CHAPSO preparation (103 vs 88 proteins, respectively).

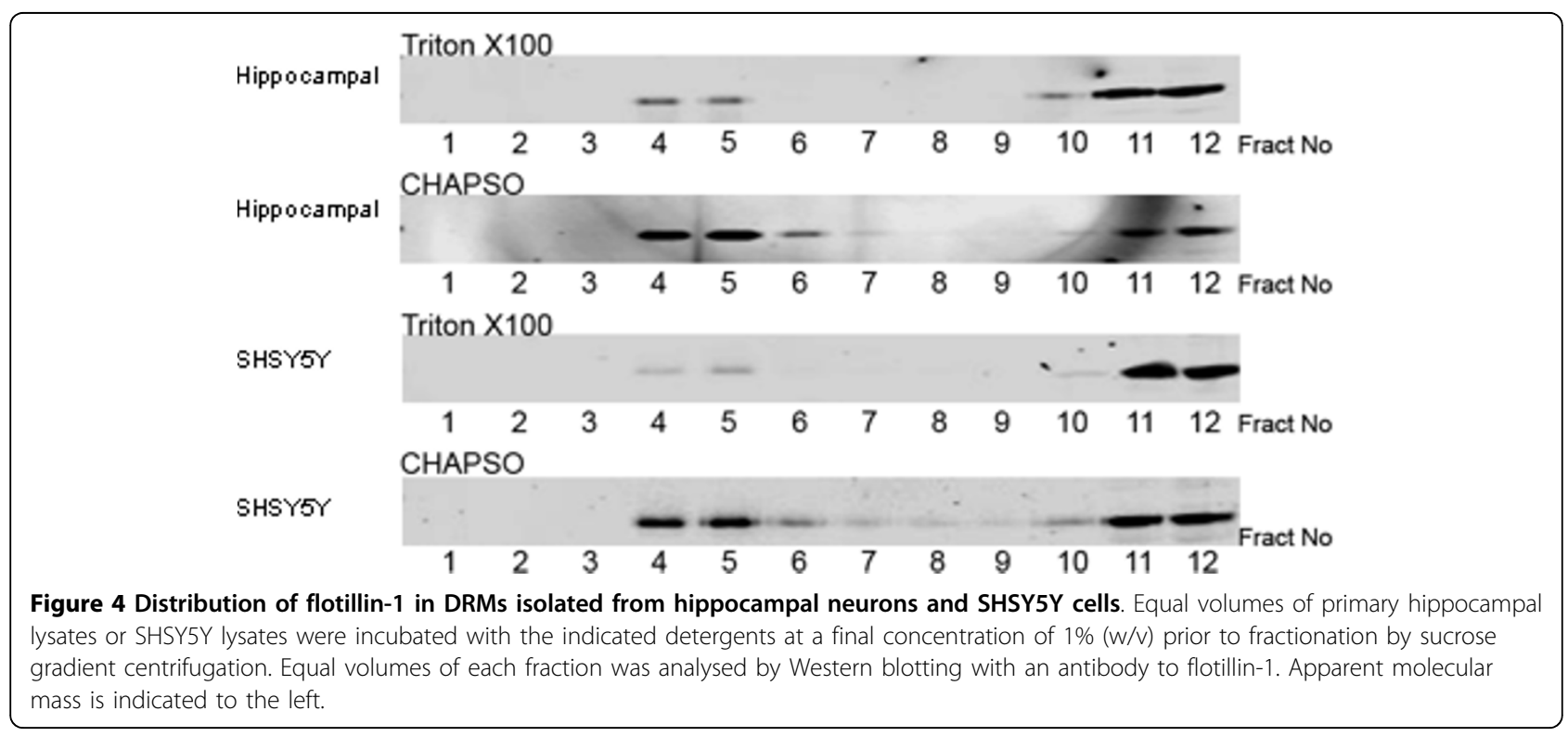




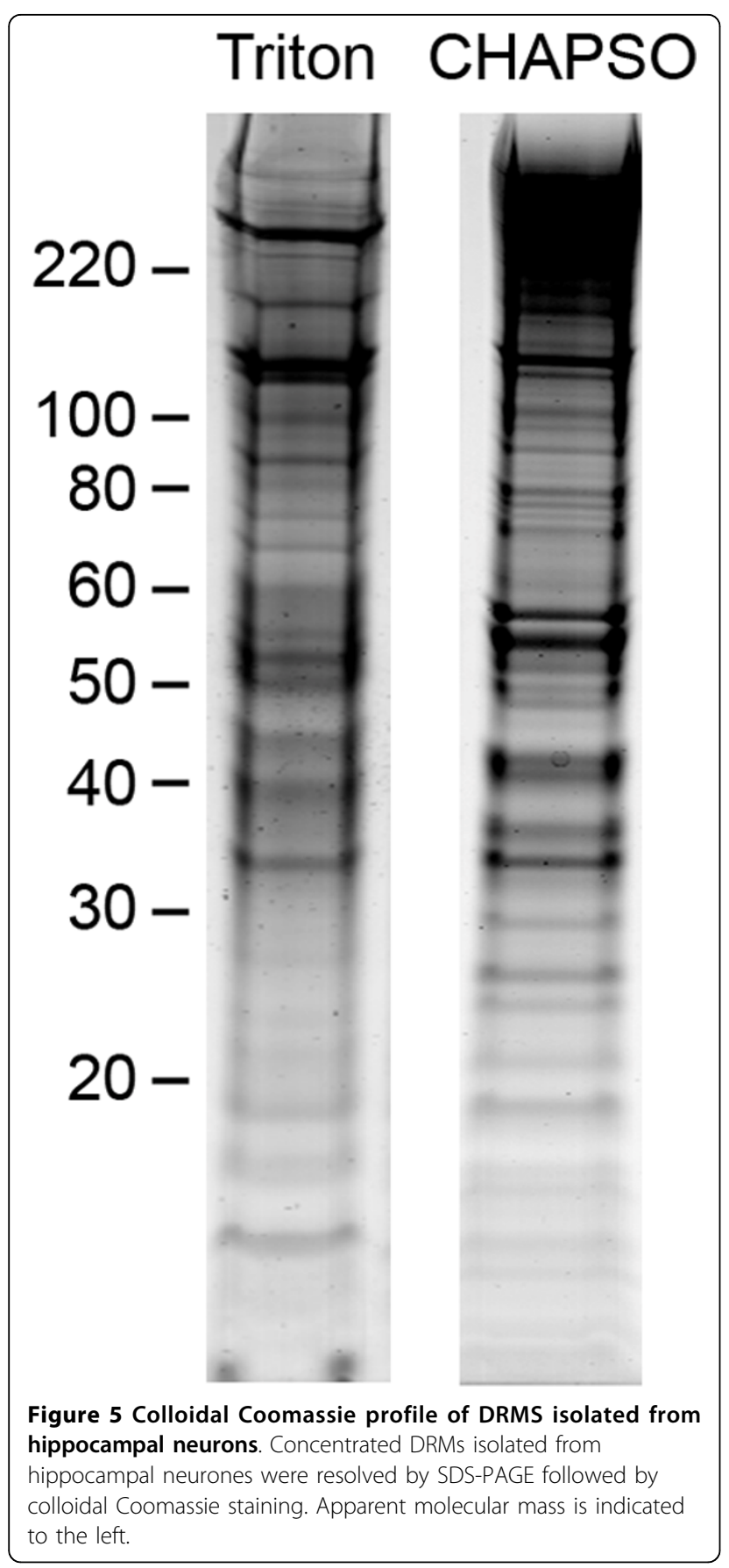

Comparison of cellular compartmentalisation of the proteins isolated in each of the preparations revealed an increase in the relative amount (expressed as percent of total DRM proteins) of cytoskeletal/filament proteins isolated in the Triton preparation compared to the CHAPSO preparation (Table 2). There was also an enrichment of endoplasmic reticulum (ER) and Golgi associated proteins in the CHAPSO preparation. Both preparations had a similar proportion of plasma
Table 2 The number of proteins identified in the CHAPSO and Triton raft preparations according to cellular component categories

\begin{tabular}{lrrr}
\hline Cellular component & \multicolumn{3}{c}{ Unique protein assignments } \\
\cline { 2 - 4 } & CHAPSO & TX100 & Combined \\
\hline Cytoplasm & 31 & 25 & 33 \\
Cytoskeleton/Filament & 24 & 42 & 43 \\
Endosome/Lysosome & 14 & 4 & 14 \\
ER/Golgi & 54 & 9 & 54 \\
Mitochondrion & 69 & 54 & 77 \\
Nucleus & 6 & 5 & 7 \\
Other & 80 & 45 & 91 \\
Plasma membrane & 104 & 62 & 106 \\
Synapse & 45 & 35 & 53 \\
Vesicle & 10 & 7 & 11 \\
Total Proteins & 437 & 288 & 489 \\
\hline
\end{tabular}

membrane associated proteins suggesting that the enrichment of membrane proteins in the CHAPSO preparation was in part due to the increased isolation of membrane bound ER, Golgi, and endosome associated proteins. In addition, both preparations contained an identical enrichment of GPI-anchored proteins, although more lipid-anchored proteins were isolated in the CHAPSO preparation. Collectively, this data indicated a higher and more specific recovery of membrane and lipid anchored proteins in the CHAPSO DRM preparations. Proteins were further characterised with respect to function. Overall, there appeared to be a similar profile of proportional enrichment by functional classification with one obvious exception. There was a greater than two-fold increase in cell structure and adhesion proteins in the Triton preparation.

To investigate further proteomic differences, the relative abundance of proteins identified in the two samples was estimated by crude semi-quantitative analysis using spectral counting (Additional file 1, Table S1), similar to recent proteomic studies $[28,29]$. Several proteins including the well-characterised raft marker proteins flotillin-1 and -2 and Thy- 1 were identified by a high number of peptides in both preparations, suggesting they were abundantly present in both raft preparations. In contrast, numerous other proteins were evidenced by confident detection of many peptides in one sample but markedly fewer or no peptides in the other, clearly indicating differing enrichment of some specific protein sub-classes. This included clear enrichment of some channels/receptors, synaptic proteins and rab proteins by CHAPSO but not by Triton (Additional file 2, Table S2), and conversely enrichment of several cell adhesion/structural components and ras GTPase activators/regulators by Triton but not by CHAPSO (Additional file 3, Table S3). 


\section{CHAPSO}

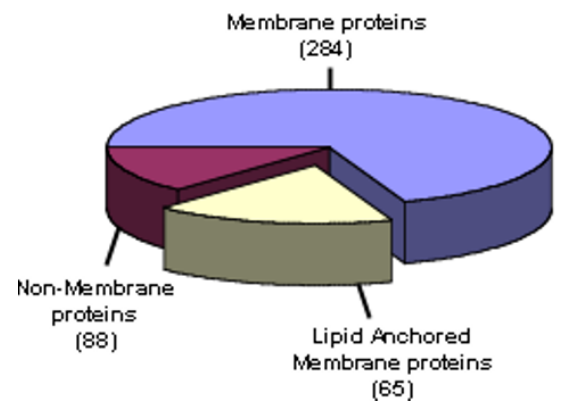

Triton X100

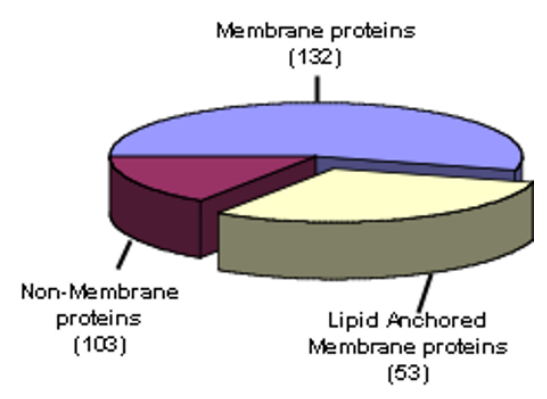

Figure 6 Distributions of membrane and non-membrane proteins identified by proteomic profiling of the CHAPSO and Triton DRM preparations. Membrane localisations were assigned based on protein annotations listed in the Uniprot database in conjunction with the transmembrane prediction algorithm Phobius. The pie slice areas represent the number of proteins in each category (listed in parentheses) as a proportion of the total number of proteins identified in each DRM preparation.

\section{Discussion}

We report here detergent-dependent variation in the enrichment of isolated DRMs with respect to cholesterol and protein. In addition, enrichment of the lipid raft marker flotillin-1 in the isolated DRMs differed greatly between the detergents tested. Of note, Triton solubilised the majority of flotillin-1 in all cells tested (hippocampal, cortical, SHSY5Y) with less than $10 \%$ of total flotillin-1 partitioning into low-density fractions. The order of DRM enrichment for flotillin-1 is CHAPSO > Brij $58>$ Brij $98>$ Triton. There was little difference in the amount of protein recovered in the low-density fractions between CHAPSO and both the Brij detergents. However, consistent with the poor enrichment of flotillin-1 in the Triton extracted DRMs, Triton proved to be very poor at enriching protein in low-density fractions when compared with the other detergents. Membrane rafts by definition are cholesterol rich, and so we examined the ability of each of the detergents to enrich for cholesterol in DRMs. In primary neuronal cultures, the order of DRM enrichment for cholesterol is CHAPSO > Brij $58>$ Brij $98>$ Triton, identical to DRM enrichment for flotillin 1 . This order of selectivity of detergents in their ability to enrich DRMs is cell type-dependent as both CHAPSO and Triton have been reported to be equally effective at DRM enrichment and more effective than both Brij 98 and Brij 58 in Jurkat and MadinDarby canine kidney cells [25]. In addition, we show here that membrane rafts can be isolated from neuronal cells at physiological temperatures with Brij 98 and that these DRMs are particularly enriched in cholesterol and flotillin-1. Our comparison of different detergents clearly showed the greatest difference between CHAPSO and
Triton in their ability to enrich cholesterol, protein, and known membrane raft markers in DRMs.

Proteomic characterisation of neuronal DRMs isolated with CHAPSO and Triton further demonstrated considerable differences between the two DRMs. As expected, there was a high representation of plasma membrane proteins within the isolated DRMs. Consistent with other non-neuronal proteomic studies of DRMs, neuronal DRMs contained multiple proteins from a number of intracellular organelles [30,31]. There was a high concentration of mitochondrial-associated proteins present in CHAPSO and Triton DRMs, $16 \%$ and $19 \%$ respectively. As yet there is no consensus about the presence of mitochondrial proteins as membrane raft components. Numerous proteomic studies have reported the presence of mitochondrial proteins [32,33], in particular ATP synthase subunits. However, only a few particular mitochondrial proteins are not restricted to mitochondria and are resident proteins in membrane rafts [30]. By determining the cholesterol dependence of mitochondrial proteins and application of high resolution linear density centrifugation, it has been reported that the majority of these proteins co-purify with DRMs but are not raft specific [34]. Our results also suggest that mitochondrial proteins isolated in DRMs are not cholesterol dependent as there was a 15 -fold increase in the cholesterol extracted DRMs compared to Triton extracted DRMs but a similar representation of mitochondrial proteins in both preparations. Our profile also included a number of ER Golgi and endosomal proteins consistent with recent studies identifying DRMs in these intracellular organelles [35-40]. In addition there was an enrichment of cell type specific neuronal proteins such as synaptic and adhesion proteins. Membrane rafts are reported to be involved in a number of different cellular 
processes including cell signalling and endocytosis. The abundance of kinases and phosphatases as well as ras GTPases detected in our DRMs is in support of these domains having such roles. In addition, the neuronal DRMs characterised here also contained an abundance of synaptic and receptor proteins specific to neurotransmission and synaptic maintenance.

Assigning functional classification and cellular compartmentalisation highlights a number of proteins that should not be present in membrane rafts but are present in both DRM preparations, such as the non-membrane nuclear histones. While these proteins clearly seem out of place in a profile of putative membrane raft proteins, other proteins which would appear to be contaminants may indeed be membrane raft resident. The transferrin receptor protein, which is traditionally regarded as a non-raft marker was identified in CHAPSO isolated DRMs by mass spectrometry. As suggested by other DRM proteomic studies this could also be a contaminant, however we cannot exclude the possibility that mass spectrometry has identified the small proportion of palmitoylated transferrin receptor that has been reported to translocate into membrane raft domains [41]. Recent proteomic studies have suggested that approximately one-third of proteins isolated by detergent extraction are either contaminants or co purifying non raft associated proteins [42]. Further work utilising cholesterol depletion studies will aid in delineating membrane raft and membrane raft-associated proteins from protein contaminants.

Our proteomic data show that there is considerable overlap between the two DRM preparations. Approximately $81 \%$ of proteins identified in the Triton DRM were also detected in the CHAPSO DRM. This included all the GPI-linked proteins and all the dually acylated (palmitoylated and myristoylated) proteins, lipid modifications involved in targeting proteins to membrane rafts [43]. The data would suggest that both detergents isolate a core set of membrane raft proteins, plus a detergent specific enrichment of a subset of proteins. Detergent extraction also disrupts lipid protein interactions, and the extent of disruption of these lipid protein interactions is evident in both DRMs. The cortical actin cytoskeleton has been reported to be involved in membrane raft formation. The enrichment of cytoskeletal proteins in the Triton DRM preparation suggests that Triton is particularly poor at disrupting the membrane raft cytoskeleton interaction, while CHAPSO is more stringent at disrupting actin membrane raft interactions.

Over 150 more proteins were identified in the DRM preparation isolated using CHAPSO compared to Triton X100 providing a more comprehensive overview of the DRM proteomic composition in keeping with the increase in protein isolated in the respective DRMs. In addition, there was a clear increase in selectivity of CHAPSO in enriching both ER/Golgi and endosomal proteins when compared to Triton.

Importantly, some known raft proteins including cytochrome B5 reductase, which clusters in neuronal plasma membrane rafts [44] and plasma membrane $\mathrm{Ca}^{2+}$ -ATPases [27] were only identified in the CHAPSO DRM preparation. Critically for neurological studies, receptors and channels instrumentally involved with synaptic neurotransmission including glutamate/aspartate excitatory amino acid transporter- 1 and -2 , glutamate receptors AMPA-1 and -2 , and GABA receptors, which are known to cluster in membrane rafts [16], were greatly enriched in the CHAPSO DRM preparation. Similarly, proteins involved in neurological disorders including $\gamma$-secretase components, integral to processing of the amyloid precursor protein implicated in the progression of Alzheimer's disease [45], neurexins and neuroligins implicated in autism and schizophrenia [46-48] were also clearly enriched (Table 3).

\section{Conclusions}

These results indicate that CHAPSO DRM preparations are especially suited to directly investigate the role of

\section{Table 3 Selected known raft proteins and proteins associated with neurological disease identified in the CHAPSO and Triton preparations}

\begin{tabular}{|c|c|c|c|c|}
\hline & \multirow[t]{2}{*}{ Accession } & \multirow[t]{2}{*}{ Protein Description } & \multicolumn{2}{|c|}{$\begin{array}{l}\text { \# Assigned } \\
\text { spectra }\end{array}$} \\
\hline & & & CHAPSO & TX100 \\
\hline \multirow{5}{*}{$\begin{array}{l}\text { Known raft } \\
\text { proteins }\end{array}$} & FLOT1_RAT & Flotillin-1 & 30 & 41 \\
\hline & FLOT2_RAT & Flotillin-2 & 23 & 33 \\
\hline & NB5R1_RAT & $\begin{array}{l}\mathrm{NADH} \text {-cytochrome b5 } \\
\text { reductase } 1\end{array}$ & 4 & \\
\hline & NB5R3_RAT & $\begin{array}{l}\mathrm{NADH} \text {-cytochrome b5 } \\
\text { reductase } 3\end{array}$ & 13 & \\
\hline & THY1_RAT & $\begin{array}{l}\text { Thy-1 membrane } \\
\text { glycoprotein }\end{array}$ & 6 & 11 \\
\hline \multirow{10}{*}{$\begin{array}{l}\text { Neurological } \\
\text { disease }\end{array}$} & BASI_RAT & Basigin & 6 & 2 \\
\hline & PRIO_RAT & Major prion protein & 6 & 6 \\
\hline & NRX1A_RAT & Neurexin-1-alpha & 2 & \\
\hline & NRX2A_RAT & Neurexin-2-alpha & 3 & \\
\hline & NRX3A_RAT & Neurexin-3-alpha & 17 & 19 \\
\hline & NLGN1_RAT & Neuroligin-1 & 3 & 1 \\
\hline & NLGN3_RAT & Neuroligin-3 & 8 & 2 \\
\hline & NICA_RAT & Nicastrin & 18 & \\
\hline & PSN1_RAT & Presenilin-1 & 4 & \\
\hline & TMEDA_RAT & $\begin{array}{l}\text { Transmembrane emp24 } \\
\text { domain-containing } \\
\text { protein } 10\end{array}$ & 9 & \\
\hline
\end{tabular}


membrane rafts on neurotransmission and synaptic dysfunction in neuronal culture. The observation that greater than $95 \%$ of cholesterol was not recovered in the DRMs from Triton extracted cells strongly indicates that Triton is highly stringent solubiliser of neuronal cells and is not particularly suited to the investigation of membrane rafts in primary neuronal cells. However, without the functional specificity of cholesterol depletion we cannot comment on whether CHAPSO or Triton is more or less specific in isolating raft proteins.

The study presented here provides the first proteomic characterisation of cultured neuronal membrane rafts and highlights the inherent limitations of using a single step extraction protocol to isolate DRMs. Nonetheless, detergent based studies on membrane rafts are a useful first step protocol for examining putative membrane raft association and in comparative studies.

\section{Methods}

Reagents

All chemicals unless otherwise stated were purchased from Sigma (Gillingham, UK). The following primary antibodies were used against: fyn, flotillin-1 (BD Transduction Laboratories, Lexington, KY, USA); phosphotyrosine (4G10; Upstate, Lake Placid, NY, USA); actin (Abcam, Cambridge, UK).

\section{Primary neuronal cultures}

Primary cortical cultures were prepared from day 18 rat embryos as previously described [49]. Primary cortical cells were plated onto poly-L-lysine $(10 \mu \mathrm{g} / \mathrm{ml})$ coated $10 \mathrm{~cm}$ dishes at a $7 \times 10^{6}$ cells $/$ dish. Primary hippocampal cells were plated onto poly-L-lysine coated $10 \mathrm{~cm}$ dishes at $3 \times 10^{6}$ cells/dish. Cultures were maintained in Neurobasal medium containing B27 supplement, $2 \mathrm{mM}$ glutamine and $20 \mu \mathrm{g} / \mathrm{ml}$ gentamicin solution. Primary cortical cells were cultured for 7 days and primary hippocampal cells were cultured for 14-21 days before being used for the membrane raft isolation. Under these conditions, cultures were almost exclusively neuronal as determined by routine staining with antibodies to neurofilaments and glial fibrillary acidic protein. All studies were performed under regulations permitted by UK Home Office.

SHSY5Y cultures were maintained as previously described [50]. Cells were cultured in Eagles minimum essential medium (EMEM-F12 1:1) supplemented with $15 \% \mathrm{v} / \mathrm{v}$ FCS, $2 \mathrm{mM}$ glutamine and $20 \mu \mathrm{g} / \mathrm{ml}$ gentamicin soulution.

\section{Detergents}

Detergents used were Brij 58, Brij 98, Triton X100 and CHAPSO.

\section{Detergent resistant membrane raft isolation}

All procedures unless stated otherwise were carried out on ice and all buffers were kept at $0-4^{\circ} \mathrm{C}$ for the duration of the procedure. For whole cell lipid raft isolation $2 \times 10 \mathrm{~cm}$ dishes $\left(7 \times 10^{6}\right.$ cells/dish) were lysed directly in $1 \mathrm{ml} \mathrm{MBS}$ buffer (25 mM MES, $150 \mathrm{mM} \mathrm{NaCl}, \mathrm{pH}$ 6.5) containing $10 \mathrm{mM} \mathrm{MgCl} 2,10 \mathrm{mM} \mathrm{NaF}, 2 \mathrm{mM}$ $\mathrm{Na}_{3} \mathrm{VO}_{4}, 1 \mathrm{mM}$ EGTA, $5 \mathrm{mM}$ DTT, $0.2 \mathrm{mM}$ PMSF. 1 $\mathrm{ml}$ of lysate were then added to $1 \mathrm{ml}$ of MBS containing either 2\% w/v Brij 58, 2\% w/v Brij 98, 2\% w/v Triton $\mathrm{X} 100,2 \% \mathrm{w} / \mathrm{v}$ CHAPSO, to yield a final detergent concentration of $1 \% \mathrm{w} / \mathrm{v}$ for all detergents. Lysates were incubated on ice for $30 \mathrm{~min}$ followed by Dounce homogenisation (18 strokes). In the case of Brij 98, the lysate was incubated at $37^{\circ} \mathrm{C}$ for 10 min prior to Dounce homogenisation. The homogenate $(1 \mathrm{ml})$ was then mixed with $1 \mathrm{ml}$ of $90 \%(\mathrm{w} / \mathrm{v})$ sucrose in MBS buffer and placed in a $12 \mathrm{ml}$ ultracentrifuge tube. A discontinuous 5-35-45\% sucrose gradient was formed by layering $4 \mathrm{ml}$ of $35 \%(\mathrm{w} / \mathrm{v})$ sucrose in MBS solution on top of the $2 \mathrm{ml}$ homogenate, followed by $4 \mathrm{ml} 5 \%(\mathrm{w} / \mathrm{v})$ sucrose in MBS solution. The sample was then centrifuged at 39,000 rpm for $18 \mathrm{~h}$ at $4^{\circ} \mathrm{C}$ in a Beckman SW41 rotor. A light scattering band at the 5-35\% interface was identified that was enriched in flotillin, indicating the presence of membrane rafts. $12 \times 1 \mathrm{ml}$ fractions were collected from the top of each gradient. To concentrate membrane rafts, fractions 4-5 were diluted in $10 \mathrm{ml}$ MBS buffer containing $10 \mathrm{mM} \mathrm{NaF}$, and $2 \mathrm{mM}$ $\mathrm{Na}_{3} \mathrm{VO}_{4}$ and centrifugating at 39,000 rpm for $1 \mathrm{hr}$ in a Beckman SW41 rotor. The membrane raft-containing pellet was solubilised in $100 \mu \mathrm{l} 20 \mathrm{mM}$ Tris/8 M urea $\mathrm{pH}$ 7.4 containing $10 \mathrm{mM} \mathrm{NaF}, 2 \mathrm{mM} \mathrm{Na}_{3} \mathrm{VO}_{4}, 5 \mathrm{mM}$ DTT, and $0.2 \mathrm{mM}$ PMSF.

\section{Cholesterol and protein measurements}

Immediately prior to analysis, all raft fractions were passed through a fine gauge needle $(22 \mathrm{~g})$ twice before aliquots were taken from each of the fractions for each of the following methods. Total protein in each fraction was determined using the BCA protein assay kit (Pierce). Bovine serum albumin diluted in different fractions isolated from sucrose gradient centrifugation of relevant detergent blanks was used as standard. Total cholesterol content in each fraction was measured fluorimetrically using the Amplex Red Cholesterol Assay Kit (Invitrogen, UK).

\section{Western Blotting}

Proteins were resolved by SDS-PAGE using 10\% (w/v) polyacrylamide. Proteins were transferred to nitrocellulose (Schleicher \& Scheull, Dassel, Germany) and immunodetection was performed using Alexa Fluor ${ }^{\odot}$ 
conjugated goat anti-mouse or IRDye ${ }^{\mathrm{Tn}} 800$ conjugated affinity purified anti-Rabbit IgG (Rockland Immunochemicals Inc, Gilbertsville, PA, USA) in conjunction with an Odyssey Infrared Imaging System (Li-Cor Biosciences, Lincoln, NE, USA). Image analysis and quantification measurements were performed using the Odyssey Infrared Imaging System application software (Li-Cor Biosciences, Lincoln, NE, USA).

\section{GelC-MS/MS}

Concentrated membrane rafts were solubilised in $4 \times$ Laemmli sample buffer (Invitrogen) and membrane raft proteins resolved on a 4-12\% Bis-Tris gel (Invitrogen). Protein bands were visualised by briefly staining with colloidal Coomassie blue and the gel lane excised into 30 sections for in-gel digestion according to established protocols [51]. Briefly, the proteins were reduced with $10 \mathrm{mM}$ DTT in $100 \mathrm{mM}$ ammonium bicarbonate and free cysteine residues were alkylated with $55 \mathrm{mM}$ iodoacetamide in $100 \mathrm{mM}$ ammonium bicarbonate. The proteins were then digested with trypsin (Roche Diagnostics, UK) for $2 \mathrm{~h}$ at $37^{\circ} \mathrm{C}$ then overnight at room temperature. In-gel digested samples were fractionated by reversed-phase chromatography using an Ultimate LC system (Dionex, Camberley, UK). Peptides were resolved on a C18 PepMap column (75 mm I.D.) using a three-step linear gradient of $0-48 \%$ acetonitrile $/ 0.05 \%$ formic acid over $120 \mathrm{~min}$ at a flow rate of $200 \mathrm{nl} / \mathrm{min}$. Peptides were ionized by electrospray ionization using a Z-spray source fitted to a QTof-micro (Waters Ltd, Elstree, UK) operating under Masslynx v3.5 software. The instrument was run in automated switching mode, selecting precursor ions based on their intensity and charge state for sequencing by collision-induced fragmentation. The MS/MS was performed using collision energy profiles that were chosen based on the mass/ charge $(\mathrm{m} / \mathrm{z})$ ratios. Raw data were recalibrated against internal tryptic peptides and processed into peak lists using ProteinLynx Global Server V2.2.5 with the following MS/MS processing parameters: smoothing by Savitzky-Golay method, 2 iterations, 4 channels; peak centroiding top $80 \%$, no deisotoping or background subtraction.

\section{Protein identification}

Proteins were identified by searching the MS peak list data for each raft profile against the Swissprot database from Uniprot version $13.2 \mathrm{http} / /$ www.expasy.org/ as a single merged search using the Mascot V2.2 search engine http://www.matrixscience.com/. The following parameter specifications were employed: Precursor ion mass tolerance 1.2 Da, fragment ion mass tolerance 0.6 $\mathrm{Da}$, species restricted to rattus norvegicus $(6939$ entries), tryptic peptides with up to two missed cleavages, variable modifications: carbamidomethylation of cysteine residues, methionine oxidation, and pyroglutamisation of $\mathrm{N}$-terminal glutamine residues. A high ion mass tolerance was used to account for incorrect precursor isotope selection that occasionally occurs during data acquisition with Masslynx V3.5. With the exception of these cases, mass accuracy was typically less than $50 \mathrm{ppm}$. Scaffold V2.1.1 (Proteome Software Inc., Portland, OR) was used to validate MS/ MS based peptide and protein identifications. DAT files for each raft profile were loaded into Scaffold as a combined MuDPIT experiment. Peptide identifications were accepted if they could be established at greater than $95 \%$ probability as specified by the Peptide Prophet algorithm [52]. Protein identifications were automatically accepted if they contained at least one unique peptide assignment and could be established at 99\% identification probability or greater by the Protein Prophet algorithm [53]. Protein identifications scoring between $95 \%$ and $99 \%$ probability were validated by manual inspection according to accepted procedures. All other returned protein hits were rejected. Functional and localisation annotations for proteins were assigned using the information in the Uniprot database http://www.uniprot.org and the transmembrane prediction algorithm Phobius [54].

\section{Additional material}

Additional file 1: Supplementary Table S1

Additional file 2: Supplementary Table S2.

Additional file 3: Supplementary Table S3.

\section{Acknowledgements}

This work was supported by grants from the Alzheimer's Disease Society, the Alzheimer's Research Trust and the Medical Research Council.

\section{Author details}

${ }^{1}$ MRC Centre for Neurodegeneration Research, Institute of Psychiatry, King's College London, London, UK. ${ }^{2}$ Biomedical Research Institute, University of Dundee, Ninewells Medical School, Dundee, UK.

\section{Authors' contributions}

RW conceived the study and carried out the biochemical separation of membrane rafts and Western blotting and protein concentration measurements. In addition RW participated in the design of the study and drafted the manuscript. AJT carried out the mass spectrometry and protein identification and participated in drafting the manuscript. MA performed the cholesterol measurements. AH participated in establishing and maintaining primary neuronal and cell line cultures. AU participated in the biochemical separation of membrane rafts, Western blotting and neuronal culture. SL participated in mass spectroscopy and protein identification. BHA contributed to manuscript preparation and study design. DPH contributed to manuscript preparation and study design. All authors read and approved the final manuscript.

\section{Competing interests}

The authors declare that they have no competing interests. 
Received: 16 March 2010 Accepted: 22 September 2010

Published: 22 September 2010

\section{References}

1. Pike L: Rafts defined: a report on the Keystone Symposium on Lipid Rafts and Cell Function. J Lipid Res 2006, 47(7):1597-1598.

2. Simons K, Toomre D: Lipid rafts and signal transduction. Nat Rev Mol Cell Biol 2000, 1(1):31-39.

3. Schroeder RJ, Ahmed SN, Zhu Y, London E, Brown DA: Cholesterol and sphingolipid enhance the Triton X-100 insolubility of glycosylphosphatidylinositol-anchored proteins by promoting the formation of detergent-insoluble ordered membrane domains. J Biol Chem 1998, 273(2):1150-1157.

4. Brown DA, Rose JK: Sorting of GPI-anchored proteins to glycolipidenriched membrane subdomains during transport to the apical cell surface. Cell 1992, 68(3):533-544.

5. Hooper NM, Turner AJ: Ectoenzymes of the kidney microvillar membrane. Differential solubilization by detergents can predict a glycosylphosphatidylinositol membrane anchor. Biochem J 1988, 250(3):865-869.

6. Schroeder R, London E, Brown D: Interactions between saturated acyl chains confer detergent resistance on lipids and glycosylphosphatidylinositol (GPI)-anchored proteins: GPI-anchored proteins in liposomes and cells show similar behavior. Proc Natl Acad Sci USA 1994, 91(25):12130-12134.

7. Eckert GP, Igbavboa U, Muller WE, Wood WG: Lipid rafts of purified mouse brain synaptosomes prepared with or without detergent reveal different lipid and protein domains. Brain Res 2003, 962(1-2):144-150.

8. Gielen E, Baron W, Vandeven M, Steels P, Hoekstra D, Ameloot M: Rafts in oligodendrocytes: evidence and structure-function relationship. Glia 2006, 54(6):499-512.

9. Ma L, Huang YZ, Pitcher GM, Valtschanoff JG, Ma YH, Feng LY, Lu B, Xiong WC, Salter MW, Weinberg RJ, et al: Ligand-dependent recruitment of the ErbB4 signaling complex into neuronal lipid rafts. J Neurosci 2003, 23(8):3164-3175.

10. Guirland C, Suzuki S, Kojima M, Lu B, Zheng JQ: Lipid rafts mediate chemotropic guidance of nerve growth cones. Neuron 2004, 42(1):51-62.

11. Kamiguchi $\mathrm{H}$ : The region-specific activities of lipid rafts during axon growth and guidance. J Neurochem 2006, 98(2):330-335.

12. Hering $H$, Lin CC, Sheng M: Lipid rafts in the maintenance of synapses, dendritic spines, and surface AMPA receptor stability. J Neurosci 2003, 23(8):3262-3271

13. Tsui-Pierchala BA, Encinas M, Milbrandt J, Johnson EM Jr: Lipid rafts in neuronal signaling and function. Trends Neurosci 2002, 25(8):412-417.

14. Zhu D, Xiong WC, Mei L: Lipid rafts serve as a signaling platform for nicotinic acetylcholine receptor clustering. J Neurosci 2006, 26(18):4841-4851.

15. Li X, Serwanski DR, Miralles CP, Bahr BA, De Blas AL: Two pools of Triton X100 -insoluble $\operatorname{GABA}(A)$ receptors are present in the brain, one associated to lipid rafts and another one to the post-synaptic GABAergic complex. J Neurochem 2007, 102(4):1329-1345.

16. Allen JA, Halverson-Tamboli RA, Rasenick MM: Lipid raft microdomains and neurotransmitter signalling. Nat Rev Neurosci 2007, 8(2):128-140.

17. Benarroch EE: Lipid rafts, protein scaffolds, and neurologic disease. Neurology 2007, 69(16):1635-1639.

18. Simons K, Ikonen E: Functional rafts in cell membranes. Nature 1997 , 387(6633):569-572

19. Ledesma MD, Da Silva JS, Schevchenko A, Wilm M, Dotti CG: Proteomic characterisation of neuronal sphingolipid-cholesterol microdomains: role in plasminogen activation. Brain Res 2003, 987(1):107-116.

20. Ponce J, Brea D, Carrascal M, Guirao V, Degregorio-Rocasolano N, Sobrino T, Castillo J, Davalos A, Gasull T: The effect of simvastatin on the proteome of detergent-resistant membrane domains: Decreases of specific proteins previously related to cytoskeleton regulation, calcium homeostasis and cell fate. Proteomics 10(10):1954-1965.

21. Locke D, Liu J, Harris AL: Lipid rafts prepared by different methods contain different connexin channels, but gap junctions are not lipid rafts. Biochemistry 2005, 44(39):13027-13042.

22. Radeva G, Sharom FJ: Isolation and characterization of lipid rafts with different properties from RBL-2H3 (rat basophilic leukaemia) cells. Biochem J 2004, 380(Pt 1):219-230.
23. Taylor CM, Coetzee T, Pfeiffer SE: Detergent-insoluble glycosphingolipid/ cholesterol microdomains of the myelin membrane. J Neurochem 2002, 81(5):993-1004.

24. Pike LJ: Lipid rafts: heterogeneity on the high seas. Biochem J 2004, 378(Pt 2):281-292.

25. Schuck S, Honsho M, Ekroos K, Shevchenko A, Simons K: Resistance of cell membranes to different detergents. Proc Natl Acad Sci USA 2003, 100(10):5795-5800

26. Drevot P, Langlet C, Guo XJ, Bernard AM, Colard O, Chauvin JP, Lasserre R, He HT: TCR signal initiation machinery is pre-assembled and activated in a subset of membrane rafts. EMBO J 2002, 21(8):1899-1908.

27. Jiang L, Fernandes D, Mehta N, Bean JL, Michaelis ML, Zaidi A: Partitioning of the plasma membrane Ca2+-ATPase into lipid rafts in primary neurons: effects of cholesterol depletion. J Neurochem 2007, 102(2):378-388.

28. Behan AT, Byrne C, Dunn MJ, Cagney G, Cotter DR: Proteomic analysis of membrane microdomain-associated proteins in the dorsolateral prefrontal cortex in schizophrenia and bipolar disorder reveals alterations in LAMP, STXBP1 and BASP1 protein expression. Mol Psychiatry 2009, 14(6):601-613.

29. Gilchrist A, Au CE, Hiding J, Bell AW, Fernandez-Rodriguez J, Lesimple S, Nagaya H, Roy L, Gosline SJ, Hallett M, et al: Quantitative proteomics analysis of the secretory pathway. Cell 2006, 127(6):1265-1281.

30. Bae TJ, Kim MS, Kim JW, Kim BW, Choo HJ, Lee JW, Kim KB, Lee CS, Kim JH, Chang SY, et al: Lipid raft proteome reveals ATP synthase complex in the cell surface. Proteomics 2004, 4(11):3536-3548.

31. Zhang N, Shaw AR, Li N, Chen R, Mak A, Hu X, Young N, Wishart D, Li L: Liquid chromatography electrospray ionization and matrix-assisted laser desorption ionization tandem mass spectrometry for the analysis of lipid raft proteome of monocytes. Anal Chim Acta 2008, 627(1):82-90.

32. Bini L, Pacini S, Liberatori S, Valensin S, Pellegrini M, Raggiaschi R, Pallini V, Baldari $C T$ : Extensive temporally regulated reorganization of the lipid raft proteome following T-cell antigen receptor triggering. Biochem J 2003, 369(Pt 2):301-309.

33. McMahon KA, Zhu M, Kwon SW, Liu P, Zhao Y, Anderson RG: Detergentfree caveolae proteome suggests an interaction with ER and mitochondria. Proteomics 2006, 6(1):143-152.

34. Zheng YZ, Berg KB, Foster L: Mitochondria do not contain lipid rafts, and lipid rafts do not contain mitochondrial proteins. J Lipid Res 2009, 50(5):988-998.

35. Browman DT, Resek ME, Zajchowski LD, Robbins SM: Erlin-1 and erlin-2 are novel members of the prohibitin family of proteins that define lipid-raftlike domains of the ER. J Cell Sci 2006, 119(Pt 15):3149-3160.

36. Campana V, Sarnataro D, Fasano C, Casanova P, Paladino S, Zurzolo C: Detergent-resistant membrane domains but not the proteasome are involved in the misfolding of a PrP mutant retained in the endoplasmic reticulum. J Cell Sci 2006, 119(Pt 3):433-442.

37. Dermine JF, Duclos S, Garin J, St-Louis F, Rea S, Parton RG, Desjardins M: Flotillin-1-enriched lipid raft domains accumulate on maturing phagosomes. J Biol Chem 2001, 276(21):18507-18512.

38. Fivaz M, Vilbois F, Thurnheer S, Pasquali C, Abrami L, Bickel PE, Parton RG, van der Goot FG: Differential sorting and fate of endocytosed GPIanchored proteins. EMBO J 2002, 21(15):3989-4000.

39. Gagescu R, Demaurex N, Parton RG, Hunziker W, Huber LA, Gruenberg J: The recycling endosome of Madin-Darby canine kidney cells is a mildly acidic compartment rich in raft components. Mol Biol Cell 2000, 11(8):2775-2791

40. Sobo K, Chevallier J, Parton RG, Gruenberg J, van der Goot FG: Diversity of raft-like domains in late endosomes. PLOS One 2007, 2(4):e391.

41. Calzolari A, Raggi C, Deaglio S, Sposi NM, Stafsnes M, Fecchi K, Parolini I, Malavasi F, Peschle C, Sargiacomo M, et al: TfR2 localizes in lipid raft domains and is released in exosomes to activate signal transduction along the MAPK pathway. J Cell Sci 2006, 119(Pt 21):4486-4498.

42. Foster $L$, De Hoog CL, Mann M: Unbiased quantitative proteomics of lipid rafts reveals high specificity for signaling factors. Proc Natl Acad Sci USA 2003, 100(10):5813-5818.

43. Zacharias DA, Violin JD, Newton AC, Tsien RY: Partitioning of lipidmodified monomeric GFPs into membrane microdomains of live cells. Science 2002, 296(5569):913-916.

44. Samhan-Arias AK, Garcia-Bereguiain MA, Martin-Romero FJ, GutierrezMerino C: Clustering of plasma membrane-bound cytochrome b5 
reductase within 'lipid raft'microdomains of the neuronal plasma membrane. Mol Cell Neurosci 2009, 40(1):14-26.

45. Thinakaran G, Koo EH: Amyloid precursor protein trafficking, processing, and function. J Biol Chem 2008, 283(44):29615-29619.

46. Kim HG, Kishikawa S, Higgins AW, Seong IS, Donovan DJ, Shen Y, Lally E, Weiss LA, Najm J, Kutsche K, et al: Disruption of neurexin 1 associated with autism spectrum disorder. Am J Hum Genet 2008, 82(1):199-207.

47. Pardo CA, Eberhart CG: The neurobiology of autism. Brain Pathol 2007, 17(4):434-447.

48. Rujescu D, Ingason A, Cichon S, Pietilainen OP, Barnes MR, Toulopoulou T, Picchioni M, Vassos E, Ettinger $U$, Bramon $E$, et al: Disruption of the neurexin 1 gene is associated with schizophrenia. Hum Mol Genet 2009, 18(5):988-996.

49. Williamson R, Scales T, Clark BR, Gibb G, Reynolds CH, Kellie S, Bird IN, Varndell IM, Sheppard PW, Everall I, et al: Rapid tyrosine phosphorylation of neuronal proteins including tau and focal adhesion kinase in response to amyloid-beta peptide exposure: involvement of Src family protein kinases. J Neurosci 2002, 22(1):10-20.

50. Thompson AJ, Williamson R, Schofield E, Stephenson J, Hanger D, Anderton B: Quantitation of glycogen synthase kinase-3 sensitive proteins in neuronal membrane rafts. Proteomics 2009, 9(11):3022-3035.

51. Shevchenko A, Chernushevic I, Wilm M, Mann M: "De novo" sequencing of peptides recovered from in-gel digested proteins by nanoelectrospray tandem mass spectrometry. Mol Biotechnol 2002, 20(1):107-118.

52. Keller A, Nesvizhskii Al, Kolker E, Aebersold R: Empirical statistical model to estimate the accuracy of peptide identifications made by MS/MS and database search. Anal Chem 2002, 74(20):5383-5392.

53. Nesvizhskii Al, Keller A, Kolker E, Aebersold R: A statistical model for identifying proteins by tandem mass spectrometry. Anal Chem 2003, 75(17):4646-4658.

54. Kall L, Krogh A, Sonnhammer EL: A combined transmembrane topology and signal peptide prediction method. J Mol Biol 2004, 338(5):1027-1036.

doi:10.1186/1471-2202-11-120

Cite this article as: Williamson et al: Isolation of detergent resistant microdomains from cultured neurons: detergent dependent alterations in protein composition. BMC Neuroscience 2010 11:120.

\section{Submit your next manuscript to BioMed Central and take full advantage of:}

- Convenient online submission

- Thorough peer review

- No space constraints or color figure charges

- Immediate publication on acceptance

- Inclusion in PubMed, CAS, Scopus and Google Scholar

- Research which is freely available for redistribution

Submit your manuscript at www.biomedcentral.com/submit
Biomed Central 